\title{
HEINZ POST
}

Der Anwendungsbereich des Unterschlagungstatbestandes

(§ 246 StGB) 


\section{NEUE KÖLNER RECHTSWISSENSCHAFTLICHE ABHANDLUNGEN}

HER AUSGEGEBEN VON

DER RECHTSWISSENSCHAFTLICHEN FAKULTAT

DER UNIVERSITAT $Z$ U KOLN

\section{HEFT 6}

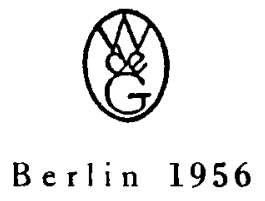

WALTER DE GRUYTER \& CO.

vormals G. J. Göschen'sche Verjagshandlung · J.Guttentag, Verlagsbuchbandlung

Georg Reimer - Karl J.Trübner - Veit \& Comp. 


\title{
Der Anwendungsbereich des Unterschlagungstatbestandes ( $\$ 246$ StGB.)
}

\author{
Vour \\ Dr. Heinz Post
}

Wuppertal

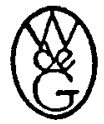

Berlin 1956

\section{WALTER DE GRUYTER \& CO.}

จormals G.J. Göschen'sche Verlagshandlung · J. Guttentag, Verlagsbuchhandlung Georg Reimer - Karl J. Trübner - Veit \& Comp. 
Archiv-Nr. $270855 / 6$

Satz und Druck: I/10/14 Walter de Gruyter \& Co., Trebbin Kr. Luckenwalde Alle Rechte, einschl. der Rechte der Herstellung von Photokopien u. Mikrofilmen, vorbehalten $5000 / 324 / 54$ 